\title{
REGENERATION ORIENTATION IS BETTER THAN RESISTANCE ORIENTATION IN BEHAVIOUR ACTIVATION. RESULTS FROM AN INTERVENTION STUDY WITH PSYCHOSOMATIC PATIENTS
}

\author{
Josephine Otto \& Michael Linden \\ Research Group Psychosomatic Rehabilitation, Charité University Medicine Berlin, Berlin, Germany
}

received: 29.11.2016;

revised: 15.3.2017;

accepted: 1.4.2017

\begin{abstract}
SUMMARY
The meaning of positive activities in mental health is widely known and found its entrance in therapeutically and empirical work. It also found it's entrance to current therapeutic developments. Different strategies for assessment and promotion of activity level exist. Patients were acquired from a department of psychosomatic medicine in a German rehabilitation center and randomly allocated to two treatment groups ("regeneration" vs "resistance" group). Data from 62 patients in the regeneration group and 65 patients in the resistance group was compared with 43 patients who received a "treatment as usual". All group comparisons were statistically significant, with different results depending on the type of activities. Regarding behavior activation, there tend to be an advantage for the regeneration group. Nothing is said about the transfer after discharge and long term effects.
\end{abstract}

Key words: behavior activation - psychosomatic - intervention

\section{INTRODUCTION}

The meaning of positive activities in mental health is widely known since the 1970s and found its entrance in therapeutically and empirical work in the treatment of depression, dementia, chronic physical illness and working with elderly (Katz et al. 1963, Lawton \& Brody 1969, Pöhlmann \& Hofer 1995, Ferster 1973, Lewinsohn \& Libet 1972). In the field of depression, behavior activation is a standard treatment and it's efficacy had widely been shown (Sin \& Lyubormirsky 2009, Mazzuchelli et al. 2010), also for prevention of dementia (Verghese et al. 2008) or heart diseases (Hu et al. 2007) the level of activities seems to be important. Goodman et al. (2016) furthermore pointed the importance of recreational activities for the association of depressive symptoms in context with life-stressors.

Behavior activation is part of current therapeutically developments: positive psychological interventions (Seligman et al. 2005) or well-being therapy (Fava 2011, Fava \& Tomba 2009) refer to the extension of positive or well-being promotional activities. In the beginning sessions in well-being therapy starts with diary methods and mindful perceptions of the association between mood and well-being. In the final sessions the planning and exercise of pleasant activities is a fixed content. The positive effects on affective and anxiety disorders, prevention in childhood and youth and the prevention of a relapse in depression had been shown.

\section{Measuring activities}

Another question arises in the assessment of the behavior level. Since the second half of the $20^{\text {th }}$ century, researchers and practitioners developed different instru- ments to assess activities. One example is the "Index of activities of daily living, ADL” (Katz et al. 1963). Here especially essential activities for functioning in daily life are captured, like bathing, dressing, toileting, transfer, continence or feeding. By observer rating and differentiation if the person could do it on its own or with assistance, a sum score is calculated and the result can be classified in "full functioning" (a score of 6), "moderate impairment (a score of 4) or a severe impairment (score 2 or less) (Miller 2000). The relevance of this instrument in chronical illness or geriatric settings has been shown (e.g. Hartigan 2007). Assessing basic levels of daily functioning may be irrelevant for psychosomatic patients because of their relatively high level of functioning and self-care in contrast to elderly and dement people.

A further development is the "instrumental activities of daily living scale" (Lawton and Brody 1969). In this observer based rating, instrumental (=planned and aimed) and more complex activities found entrance, like telephoning, shopping, food preparation, housekeeping, laundry, finance competence, transport and mobility and medication and health management. Every item is scored zero or 1 and summed up (range 0 to 8 ) and lower scores indicate higher dependence. In it's almost 50 years of history, variations of ADL and IADL exist in dependence of the context they were applied (Hindmarch et al. 1998, Spector \& Fleishman 1998, Wilms et al. 1998, Potkin 2002).

When it comes to a comprehensive description of a person functioning level, the "International classification of functioning, disability and Health" (WHO 2001) provides a framework which includes components of functioning and disability and contextual factors. Independent of any illness or symptoms, the 
ICF has 1424 categories to describe the different aspects of health in detail, but it was not conducted as an assessment instrument. Several instruments were developed on basic of the ICF, like the Mini-ICF-APP Rating (e.g. Linden et al. 2009) worked as an observer based rating. Brütt and colleagues (2014) published a self-rating instrument for activities based on the ICF with activities and social participation (ICF-MentalA\&P). They used a global rating of the participants in the following scales: functioning (example: "I find it difficult to cope with everyday tasks"), communication ("I find it difficult to have a conversation with someone"), mobility ("I find it difficult to go far away from home”), relationships ("I am limited in my relationships with my family members"), recreation ("I am limited in pursuing my hobbies and favourite pastimes") and interaction ("I find it difficult to confront others with upcoming problems"). Although recreational activities found their entrance in the assessment, especially for interventions it is important to measure differential what patients actually do and by thinking within a salutotherapeutic and health promotion framework (Antonovsky 1987). Hautzinger (2008) published a "list of pleasant activities" in which patients are able to distinguish between a rating of the level of pleasant activity and the intention to do this activity in future for 222 activities. This scale is rather used in cognitive behaviour therapy in Germany and not for evaluation in scientific settings. Besides this, the Recreational Activities of Daily Life Scale (Linden et al. 2009) provides an in a psychosomatic setting developed empirical investigated instrument, which asses recreational activities in self-report. Here certain clusters were developed for a better overview and could be used in therapy planning.

\section{Intervention strategies}

Despite this well-known empirical base, intervention strategies for behavioral activation may differ in the point how this could happen efficient and sustainable?

Looking to the literature (Addis \& Martell 2004, Hopko \& Lejuez 2007, Hopko et al. 2003; Lewinsohn \& Graf 1973, Lewinsohn \& Libet 1972) behavioral activation consists of identifying activities associated with positive mood, client self-recording of engagement in pleasant activities and setting weekly, small goals and longer term goals to gradually increasing the frequency and duration of pleasant activities. In traditional, especially psychiatric, setting, patients were motivated to do activities within the treatment setting, for example in occupational therapy or working therapy (Reuster 2006). The therapeutic behavior is often forcing and motivating to show a certain performance, independently if this activities matches with personal goals of the patient. A common aim is to train certain skills to improve the patients "resistance", especially when it comes to stress-coping issues (Kobasa 1979).
In contrast to this, current therapeutic trends also force a reflection of personal meaningful activities and certain personal goals, like in well-being therapy (Fava 2011) or acceptance and commitment therapy (Hayes et al. 2004). Therapeutic strategic may focus the planning of personal meaningful activities, and the therapist is more empathic forces the individual personal goals for the patient. This works also with attention focusing, distraction and to focus on "regeneration" in a stresscoping issue.

Given the broad empirical foundation and importance of behavioral activation, the question for concrete strategies how to promote the activity level arises.

In this study, a randomized controlled trail investigates the benefit of two different therapeutic strategies: forcing the patients to "train" certain activities in the clinical setting in terms of a "resistance intervention" or motivating them to find out their own activities in a non directional way in terms of a "regeneration" interventions.

\section{SUBJECTS AND METODS}

\section{Study design}

Patients were acquired from a department of psychosomatic medicine in a German rehabilitation center. They suffer from all types of mental disorders or admitted for inpatient treatment because of sick leave or when ability to work is endangered. The inpatient stay lasts on average five weeks and includes individual and group psychotherapy, medication, social therapy, sport therapy and occupational therapy.

Participants of this study were asked to participate in an additional group therapy. After giving their written informed consent patients were randomly allocated to two treatment groups. The add-on treatment consisted of a total amount of 15 sessions, with three sessions per week with respectively 90 minutes duration. The routine group was recruited during the last week of the treatment. The study protocol has been approved by the internal review board of the German Federal Pension Agency.

\section{Treatment}

Both treatment groups didn't focus on certain symptoms or diagnosis. Besides other goals, one aim was to increase the activation level of the patients.

The "resistance-group" (ResG) focussed on frustration tolerance, stamina and endurance, accuracy, discomfort tolerance and flexibility. In each session they were given complex tasks, with no direct solutions and high demands, like handicraft, origami or soap stones, and were put under time pressure and judgements about their performance in the group. Patients were told that they should learn to cope with adversities and strains, so they can show a consistent performance of activation level. This experience can be learned in the micro context of the group session and transferred to everyday 
life. The therapeutic behaviour was supportive in the sense that participants were motivated to go on with the task despite negative internal states (like exhaustion, arousal or frustration). The therapists also focussed on mistakes in the process and motivated the patients actively to think about alternatives and motivated them during the task, also they point mistakes and failure. This principle is similar to traditional occupational or working therapies.

The "regeneration-group" (RegG) focussed on the promotion of distraction from negative and enhancement of positive emotions by doing pleasant activities. There also were discussions about meaningful life goals, like "How important is your job? Do you have any other resources?” Techniques were behavioral experiments within the group, like celebrating a tea ceremony, euthymic exercises by cooking, relaxation, recovery, deliberately fostered well-being, or the enhancement of self-care with makeup and clothing. The therapists were instructed to be very supportive, empathic, warm and at eye level with the patients. They were told to focus actively on positive emotions during the group sessions.

\section{Measurements}

Protocol adherence in reference to the treatment manuals as a manipulation check was measured with a therapy competency checklist for resistance and regeneration training (BTCC-RS), designed for this study in reference to the Behavior Therapy Competency Checklist (Linden et al. 2007) For each group, 10 items describe pivotal interventions, e.g. in the regeneration group "I was able to experience moments of indulgence", or in the resistance group "I was able to train my frustration tolerance”. The participants made a rating on a seven point Likert scale from 1 "not at all” to 7 "completely". All items were coded in the same direction and a mean for every group was calculated. The reliability (Cronbach's alpha) was 0.90 for regeneration items and 0.93 for resistance items.

\section{Activity level}

With the Checklist of Recreational Activities of daily living list (RADL) (Linden et al. 2007), a comprehensive and empirically established instrument for the measurement of the activity level exists. This gives a list of 37 items which can be grouped (see tab. 1) in "cultural activities" (e.g. listen to music), "physical activities" (e.g. jogging), "manual skills” (e.g. photography), "social recreation" (e.g. visit friends) and "home activities" (e.g. cocking). Items of the scale were in part taken from the NPI Interest Check List (Matsutsuyu 1969, Rogers et al. 1978, Klyczek et al. 1997) and the pleasant event scale (Lewinsohn \& Libet 1972) and adapted to German styles of living. In the current study, patients filled out the list at the end of their treatment. They are asked, if they had done the specific activity during the rehabilitation (Coding: 0 = never, 1 time, 2 times, 3 times und more than 3 times). All 37 activities were dummy - coded, where zero remained zero and all other values were 1 . For further calculation the activities were clustered to "cultural activities", "hobbies”, "social activities”, "physical activities” and "home activities”. Table 1 gives an overview over the clusters.

Social and clinical data, like diagnosis, private situation or volitional status, were taken from "PsyBaDo" of the hospital, which is a German-wide measurement system which routinely collects data on the patient status (Heuft et al. 1998).

\section{RESULTS}

\section{Patient sample}

During an interval of 11 months, 876 patients from a psychosomatic rehabilitation hospital were asked to attend an additional stress coping treatment. 194 (22.14\%) were interested, 10 (5.15\%) dropped out before the first session. There was no significant difference in pre-treatment distress intolerance between the interested and not interested patients $\left(\mathrm{t}_{866}=1.62\right.$, $\mathrm{p}=0.11$ ) Participants were randomized according to the last number of their internal ID (even numbers =regeneration, uneven numbers = resistance) either to the regeneration group $(n=83)$ or the resistance group $(n=101)$. 18 patients from the regeneration group (21.7\%) and 33 from the resistance group (32.7\%) dropped out during the course of treatment. Finally 65 persons completed the regeneration group and 68 the resistance group. 44 Persons were recruited for the routine group. Because of missing data eight cases had to be excluded from further analysis. The final sample consisted of 62 patients in the regeneration group, 65 in the resistance group, 43 in the routine group (total $\mathrm{N}=169$ ). There were $46.8 \%$ females in the regeneration group, $64.0 \%$ in the resistance group, and $53.5 \%$ in the routine group. The average age was 50.80 Years (Standard deviation, SD: 8.69) years in the regeneration group, 49.52 (SD: 8.74) in the resistance group, and 50.91 (SD: 8.85) in the routine group. This is a normal age for this clinical sample because of the chronical mental illness and the rehabilitation setting: people had to pay several years of social insurance fees after they were able to be admitted to a psychosomatic rehabilitation. There were no significant differences in age between the group conditions.

The clinical diagnoses of all 169 patients were mood disorders (ICD-10 F3) in $47.6 \%$ of cases, neurotic, stress-related and somatoform disorders (ICD-10 F4) in $26.6 \%$, personality disorders (ICD-10 F6) in 8.4\%, developmental disorders (ICD-10 F8,9) in 5.6\%, organic mental disorders (ICD-10 F0) in 4.9\%, eating or sleep disorders (ICD-10 F5) in 4.2\%, substance abuse disorders (ICD-10 F1) in 1.4\%, and schizophrenic disorders (ICD-10 F2) in 1.4\%, which was also typical of this setting, because substance abuse disorders require an specific allocation to special rehabilitation centers. 
Table 1. Overview of activities and used clusters

\begin{tabular}{lllll}
\hline Cultural activities & Hobbies & Social activities & Physical activities & Home activities \\
\hline Theater, Opera, Concert & Play an instrument & Parties & Swimming & Buy daily goods \\
Cinema & Manual arts & Meeting with friends & Bicycles & Cooking \\
Museum & Handicraft & Family activities & Walking/jogging & Cleaning, ironing \\
Excursions & Model building & Clubs & Go for a walk & Garden/balcony \\
Language learning & Photography & Civic engagement & Hiking & Caring for pets \\
TV/DVD & Painting & Parlour games & Sauna & \\
Listening to music & Crossword/ Sudoku & & Dancing & Yoga, Meditation, Relaxtion methods \\
Computer & & & Sport studio & \\
Reading & & & Sport courses & \\
& & &
\end{tabular}

Table 2. Differences in activity levels

\begin{tabular}{|c|c|c|c|c|c|}
\hline & $\begin{array}{l}\text { Routine } \\
\text { group } \\
\text { MW (SD) }\end{array}$ & $\begin{array}{l}\text { Regeneration } \\
\text { group } \\
\text { MW (SD) }\end{array}$ & $\begin{array}{l}\text { Resistance } \\
\text { group } \\
\text { MW (SD) }\end{array}$ & $\begin{array}{l}\text { F-value, } \\
\text { p-value }\end{array}$ & Post Hoc Tests \\
\hline Cultural activities & 5.47 (1.88) & 6.43 (1.69) & $5.61(1.80)$ & $\begin{array}{l}\mathrm{F}_{(2,211)}=5.24 \\
\mathrm{p}=0.006\end{array}$ & $\begin{array}{l}\text { RouG \& RegG: } p=0.01 \\
\text { RouG \& ResG: } p=1.00 \\
\text { RegG \& ResG: } p=0.05\end{array}$ \\
\hline Hobby activities & 2.47 (1.25) & $3.23(1.26)$ & 3.53 (1.18) & $\begin{array}{l}\mathrm{F}_{(2,221)}=15.95 \\
\mathrm{p}<0.001\end{array}$ & $\begin{array}{l}\text { RouG \& RegG: } \mathrm{p}<0.001, \\
\text { RouG \& ResG: } \mathrm{p}<0.001 \\
\text { RegG \& ResG: } \mathrm{p}=0.51\end{array}$ \\
\hline Social activities & $2.20(1.34)$ & $2.74(1.15)$ & $2.20(1.12)$ & $\begin{array}{l}\mathrm{F}_{(2,225)}=4.21 \\
\mathrm{p}=0.02\end{array}$ & $\begin{array}{l}\text { RouG \& RegG: } p=0.02, \\
\text { RouG \& ResG: } p=1.00 \\
\text { RegG \& ResG: } p=0.05\end{array}$ \\
\hline Physical activities & $4.71(1.75)$ & $5.46(1.64)$ & $4.73(1.77)$ & $\begin{array}{l}\mathrm{F}_{(2,215)}=3.91 ; \\
\mathrm{p}=0.02\end{array}$ & $\begin{array}{l}\text { RouG \& RegG: } p=0.03 \text {, } \\
\text { RouG \& ResG: } p=1.00 \\
\text { RegG \& ResG: } p=0.06\end{array}$ \\
\hline Home activities & $2.02(1.22)$ & $2.24(1.13)$ & $1.68(1.03)$ & $\begin{array}{l}F_{(2,221)}=3.86 \\
p=0.02\end{array}$ & $\begin{array}{l}\text { RouG \& RegG: } p=0.72 \\
\text { RouG \& ResG: } p=0.18 \text {, } \\
\text { RegG \& ResG: } p=0.02\end{array}$ \\
\hline
\end{tabular}

Note: Means and Standard Deviations for every cluster and every group, also F-Values and p-Values for the one way ANOVA. Explanation of Abbreviations: RouG - Routine Group, RegG - Regeneration Group, ResG - Resistance Group

\section{Manipulation check}

The mean of the regeneration items in the BTCC-RS was 5.03 (SD: 1.02) in the regeneration group, 3.58 (SD: 1.14) in the resistance group, and 3.82 (SD: 1.25) in the routine group. There was a significant overall difference between groups $\left(\mathrm{F}_{(2,160)}=27.49\right.$, $\left.\mathrm{p}<0.001\right)$ with significantly higher ratings in the regeneration group in contrast to the resistance group $(\mathrm{p}<0.001)$, and the routine group $(p<0.001)$, and no difference between the routine group and the resistance group $(\mathrm{p}=0.87)$.

The mean of the scale of the resistance items in the BTCC was 3.95 (SD: 1.28) in the regeneration group, 4.42 (SD: 1.44) in the resistance group and 3.06 (SD: 1.16) in the routine group. There was a significant difference between groups $\left(\mathrm{F}_{(2,159)}=13.17, \mathrm{p}<0.001\right)$, with a significant difference between the resistance and the routine group $(p<0.001)$, and between the routine group and the regeneration group $(\mathrm{p}=0.003)$, and no significant difference between the regeneration and the resistance group $(\mathrm{p}=0.16)$.

\section{Differences in activity levels}

For differences between the groups, a one way ANOVA for each activity cluster was calculated. All group comparisons were statistically significant (each $\mathrm{p}<0.002$ ). Looking to single group comparisons, participants of the regeneration group reported more cultural activities than the routine group $(p=0.01)$ and the resistance group $(\mathrm{p}=0.05)$. No differences between the resistance group and the routine group were observed. Regarding to hobby activities, the resistance and regeneration group participants reported more activities than the routine group (each $\mathrm{p}>0.001$ ), but there was no difference between the regeneration and resistance group $(\mathrm{p}=0.51)$, but more activities in the resistance group, looking at the descriptive values. In social activities, there was a significant difference between the regeneration and routine group $(\mathrm{p}<0.001)$ and the regeneration and the resistance group $(\mathrm{p}=0.05)$. The same pattern was found related to physical activities, but the difference between regeneration and resistance group is marginally 
significant (post-hoc test: routine group vs. regeneration group: $\mathrm{p}=0.03$, routine group vs. resistance group: $\mathrm{p}=1.00$, regeneration vs. resistance group: $\mathrm{p}=0.06$ ). In the report of home activities there was a significant difference between the resistance and the regeneration $(p=0.02)$, all other differences were non-significant in post-hoc comparisons (Routine Group vs. regeneration group: $\mathrm{p}=0.72$ Routine group vs. resistance group: $\mathrm{p}=0.18$ ) (Table 2 ).

\section{DISCUSSION AND CONCLUSIONS}

The data on protocol adherence show that different interventions were applied in the two specific groups and were reported from the patients. This results in different outcomes.

Regarding behaviour activation, there tend to be an advantage for the regeneration group. Especially in cultural and physical activities, patients show a higher level on activation during the rehabilitation treatment. This maybe caused in different reasons. Firstly, they were motivated to plan personal important and meaningful activities in the regeneration groups and actively asked for activities which were historical important to them, like underused hobbies. This leads to the point that the activation of former activities is easier than doing completely new activities. Another explanation for this result arises in the context of motivation. As Ryan and Deci (2000) stated, there is huge difference between activities done by intrinsic vs. extrinsic motivation. Intrinsic motivation is better for well-being and the sustainability of behaviours. Looking at the interventions, the regeneration group focusses more on intrinsic motivation, especially in the therapeutic behaviour.

The effects on the different clusters are mixed. Regarding to hobbies, the resistance group also showed a high level of activities. This may be caused in the point, that also during the resistance group, the patients performed hobbies like handicraft, but not in voluntary way. Nothing is said about the experience in the group with the tasks. Another result is, that participants of the resistance group showed a lower level of home activities, even compared to the control group, whereas the participants to the regeneration group showed a high level of home activities. This result may be caused in exhaustion of the resistance group, because of the demanding tasks within the group sessions. An explanation for the advantage of the regeneration group is, that in the group strategies to enhance a well-being with a comfortable and positive home environment were discussed. Maybe the participants we more motivated to clean and care for the home previously to a prettier decoration. All in all, the results suggest a benefit of the regeneration group in doing behaviour activation.

The results must be evaluated in the light of limitations. Firstly: the study had been done with the sample of psychosomatic inpatients, which may differ from other nonclinical or other clinical populations in mechanisms for behaviour activation. But the enhancement of activities can also be an important question in a non clinical sample, e.g. in a prevention or stress coping setting, like in the establishment of physical activities.

Another methodical weakness is the study design: we only had post-measures of the activity level. It is unclear how much the participants did before attending the groups. Especially if the "fitter" patients more voluntary joined the add-on therapy. This argument can be rejected partly with the randomized study design, but no further calculations can be done because of lacking data. Another issue affects the field of sustainability of activities: nothing is said about the activities after discharge. Maybe we only have short-term effect but the clinical importance arises in the field of long-term behaviour change.

Nevertheless, the study should encourage further investigations for this important psychotherapeutic treatment principle.

\section{Acknowledgements:}

The project was supported by the German Pension Fund (DRV Bund, 8011-106-31/31.51.9).

Conflict of interest: None to declare.

\section{Contribution of individual authors:}

Josephine Otto: development, implementation and supervision of the group therapy, design of the study, literature searches and analyses, statistical analyses, interpretation of data, writing of the manuscript;

Michael Linden: development and supervision of the group therapy, development and publication of the evaluation measure, completing the statistical analysis, proofreading the manuscript.

\section{References}

1. Addis M \& Martell C: Overcoming Depression One Step at a Time: The New Behavioral Activation Approach to Getting Your Life Back, New Harbinger Publications, Oakland, 2004.

2. Antonovsky A: Unraveling the Mystery of Health: How People Manage Stress and Stay Well. Jossey Bass Social and Behavioral Science Series, San Francisco, 1987.

3. Brütt AL, Schulz, H, Andreas S: Psychometric properties of an instrument to measure activities and participation according to the ICF concept in patients with mental disorders. Disability and Rehabilitation 2014; 37:259-267.

4. Fava G: Well-being therapy. In Linden $M$ \& Hautzinger M. Verhaltenstherapiemanual. Springer Berlin, Heidelberg, 2011.

5. Fava G \& Tomba E: Increasing Well-Being and Resilience by Psychotherapeutic Method. Journal of Personality 2009; 77:1903-1933.

6. Ferster CB: A Functional Analysis of Depression. American Psychologist 1973; 28:857-870. 
7. Goodman WK, Geiger AM \& Wolf JM: Differential Links Between Leisure Activities and Depressive Symptoms in Unemployed Individuals. Journal of clinical psychology 2016; 72:70-78.

8. Hartigan I: A comparative review of the Katz ADL and the Barthel Index in assessing the activities of daily living of older people. International Journal of Older People Nursing 2007; 2:204-212.

9. Hautzinger M: Kognitive Verhaltenstherapie bei Depressionen. Beltz, Weinheim, 2013.

10. Hayes SC, Madua A, Bissett R, Luoma, J \& Guerrero LF: DBT; FAP and ACT: How empirically oriented are the new behaviour therapy technologies? Behavior Therapy 2004; 35:35-54.

11. Heuft G, Senf W, Bell K, Cording C, Geyer M, Janssen $P L$, Lamprecht F, Meermann R, Strauss B \& Wirsching M: Psy-BaDo, Psychotherapeut 1998; 43:48-52.

12. Hopko, DR \& Lejuez, CW: A cancer patient's guide to overcoming depression \& anxiety: Getting through treatment \& getting back to your life. Oakland, CA: New Harbinger, 2007.

13. Hopko DR, Lejuez CW, Ruggiero KJ \& Eifert GH: Contemporary behavioral activation treatments for depression: Procedures, principles and progress. Clinical Psychology Review 2003; 23:699-717.

14. Hindmarch I, Lehfeld H, DeJongh $P$ \& Erzigkeit H: The Bayer Activities of Daily Living Scale (B-ADL) Dementia and Geriatric Cognitive Disorders 1998; 9:20-26.

15. Hu G, Tuomilehto J, Borodulin K \& Jousilahti P: The joint associations of occupational, commuting and leisure time physical activity, and the Framingham risk score on the 10-year risk of coronary heart disease. European Heart Journal 2007, 28:492-498.

16. Katz S, Ford AA, Moskowitz RW, Jackson BA \& Jaffe $M W$ : Studies of Illness in the aged. The index of $A D L$. Journal of the American. Medical Association 1963; 185:914-919.

17. Klyczek JP, Bauer-Yox $N$ \& Fiedler RC: The interest checklist: A factor analysis. The American Journal of Occupational Therapy 1997; 51:815-823.

18. Kobasa S: Stressful Life Events, Personality, and Health: An Inquiry Into Hardiness. Journal of Personality and Social Psychology 1979; 37:1-11.

19. Lawton MP \& Brody EM: Assessment of older people: Self-maintaining and instrumental activities of daily living. Gerontologist 1969; 9:179-186.

20. Lewinsohn PM \& Graf M: Pleasant activities and depression. Journal of Consulting and Clinical Psychology 1973; 41:261-268

21. Lewinsohn PM \& Libet J: Pleasant Events, Activity Schedules, and Depressions. Journal of Abnormal Psychology 1972; 79:291-295.

22. Linden M, Langhoff C \& Rotter M: Definition, operationalization, and quality assurance of psychotherapy. An investigation with the behaviour therapy-competencechecklist (BTCC). Psychiatr Danub 2007; 19:308-316.
23. Linden M, Baron S \& Muschalla B: Mini-ICF-APP - MiniICF-Rating für Aktivitäts- und Partizipationsstörungen bei psychischen Erkrankungen. Hogrefe, Göttingen, 2009.

24. Linden M, Gehrke G \& Geiselmann B: Profiles of Recreational Acitivities of Daily Living (RADL) in Patients with Mental Disorders. Psychiatr Danub 2009; 21:490-496.

25. Matsutsuyu JS: The Interest Check List. The American Journal of Occupational Therapy 1969; 23:323-328.

26. Mazzucchelli T, Kane R \& Rees CL: Behavioral activation treatments for depression in adults: a meta-analysis and review. Clinical Psychology 2009; 16:383-411.

27. Miller ME, Rejeski WJ, Reboussin BA, Ten Have TR \& Ettinger WH: Physical activity, functional limitations, and disability in older adults. Journal of the American Geriatrics Society 2000; 48: 1264-72.

28. Potkin SG: The ABC of Alzheimer's Disease: $A D L$ and Improving Day-to-Day Functioning of Patients. International Psychogeriatrics 2002; 14:7-26.

29. Pöhlmann $K$ \& Hofer J: Umwelt- und somatische Faktoren: Auswirkungen auf Hilfe- und Pflegebedarf bei älteren Menschen und die Struktur der instrumentellen Unterstützung. Zeitschrift für Gerontopsychologie und psychiatrie 1995; 8:213-226.

30. Reuster T: Effektivität der Ergotherapie im psychiatrischen Krankenhaus: Mit einer Synopse zu Geschichte, Stand und aktueller Entwicklung der psychiatrischen Ergotherapie. Monographien aus dem Gesamtgebiete der Psychiatrie. Steinkopff, Darmstadt, 112, 2006.

31. Rogers JC, Weinstein JM \& Figone JJ: The Interest Checklist: Empirical Assessment. American Journal of Occupational Therapy 1978; 32:628-630.

32. Ryan RM \& Deci EL: Intrinsic and Extrinsic Motivations: Classic Definitions and New Directions, Contemporary Educational Psychology 2000; 25: 54-67.

33. Seligmann $M$, Steen $N$, Park $N$ \& Peterson C: Positive Psychology Progress - Empirical Validation of Interventions. American Psychologist 2005; 60:410-442.

34. Sin, NL \& Lyubomirsky S: Enhancing well-being and alleviating depressive symptoms with positive psychology interventions: a practice friendly meta-analysis. Journal of clinical psychology 2009; 65:467-487.

35. Spector WD \& Fleishman JA: Combining Activities of Daily Living With Instrumental Activities of Daily Living to Measure Functional Disability. Journal of Gerontology: Social Science 1998; 53:46-57.

36. Verghese J, Lipton RB, Katz MJ., Hall CB, Derby CA, Kuslansky G, Ambrose AF, Sliwinski $M$ \& Buschke $H$ : Leisure activities and the risk of dementia in the elderly. New England Journal of Medicine 2003; 348:2508-2516.

37. Wilms HU, Baltes MM \& Kanowski S: Demenzerkrankungen und Alltagskompetenz: Effekte auch jenseits von $A D L$ und IADL. Zeitschrift für Gerontologie und Geriatrie 1998; 31:263-270.

38. World Health Organization: International Classification of Functioning, Disability and Health (ICF). WHO, Geneva, 2001.

\section{Correspondence:}

Iosephine Otto, MA

Charité University Medicine Berlin, Research Group Psychosomatic Rehabilitation

Hindenburgdamm 30, 12200 Berlin, Germany

E-mail:1fpr@charite.de 